\title{
Optimization of the parameters of the piston pin bearing of the tractor engine taking into account the solution of the lubrication problem
}

\author{
Oleg Zavyalov ${ }^{1,2, *}$ \\ ${ }^{1}$ FSBU of HE "Financial University", Chelyabinsk Branch, 454084 Chelyabinsk, Ulitsa Rabotnits, \\ 58 , Russia \\ ${ }^{2}$ Chelyabinsk State University, 454001 Chelyabinsk, Bratiev Kashirinykh street, 129, Russia
}

\begin{abstract}
The task of the investigation is to make the model, the algorithm, the program and the results of the calculations of optimization of the parameters of the bearing sliding of piston pin of the internalcombustion engine. An approximate mathematical model of dynamically loaded bearings of a piston pin of the internal-combustion engine was built up with the account of calculation methods of the statically loaded sliding bearings. The approximate mathematical model describes the relationship of output parameters of bearings of piston pin the operational and structural factors. The model is based on the method of M.V..Korovchinskiy of hydrodynamic calculation of statically loaded sliding bearings. The solution of optimization task was performed with the help of the author's program in MATLAB environment. The optimization was produced by using the gradient release method. At each iteration a step was calculated in the condition of minimum of the function of the independent variable. The program of the calculation is a finished product and it can be used at the designing of the bearings of sliding engines.
\end{abstract}

\section{Statement of the problem}

The development and improvement of internal combustion engines requires the study of hydrodynamic processes of bearings, including bearings of the piston pin. In this regard, the urgent task is to improve the design and operational characteristics of the bearings of the piston pin of the internal combustion engine.

This is a task with many parameters. Some of them are known: the pressure of grease in the bearing of the piston pin; specific heat of the oil; specific gravity of the oil; the diameter of the engine piston. For others, there are known interval constraints: bearing diametrical clearance; dynamic viscosity of the oil; maximum hydrodynamic pressure. Quadrupeds evaluation of dynamic loads of the bearing under conditions of semi-fluid, and boundary friction; increment the temperature of the lubricating layer; the eccentricity; the relationship of the length of the piston head to the diameter of the piston.

\footnotetext{
* Corresponding author: zavog@yandex.ru
} 
The required parameters are: the length of the piston head; bearing diametrical clearance; dynamic viscosity of the oil.

\section{Analysis of recent achievements and publications that have begun to address this issue}

The engine is the most complex and expensive Assembly of tractors, cars and other machinery. If the cost of manufacturing an internal combustion engine to take $100 \%$, the cost of its maintenance will be up to $25 \%$ for repairs - up to $65 \%$. That is, the cost of maintaining the reliability of the engine in operation is nine times higher than its initial cost. According to experts, $14 \%$ of the generated energy is used to overcome friction. Increasing the mechanical efficiency of the internal combustion engine by only $1 \%$ will save about $2.5 \mathrm{~g}$ of fuel per $1 \mathrm{~kW}$ of power per hour.

A significant impact on the technical level of the engine provides lubrication of its mechanisms and assemblies. With a rational lubrication process, the level of friction and wear losses will be minimal, which will increase the efficiency of the engine as a whole. An important role in understanding the mechanism of longevity plays the theory of friction and wear, developed by IP Kragelsky, Bi Kostetsky, N. L. Golego, F. Bowden, D. Tabor. The durability of the engine is limited mainly by friction pairs, the overwhelming share of mechanical losses also falls on friction pairs. An explanation of the phenomena occurring in the lubricant layer of friction pairs is provided by the hydrodynamic theory of lubrication, the foundations of which were laid by N. P. Petrov and O. Reynolds. Further development of this theory received the work of N. E. Zhukovsky, S. A. Chaplygin, A. Sperfeld. A great contribution to its development was made by F. P. Bowden, D. Tabor, N. Tipa, V. N. Constantinescu, M. V. Korovchinsky, A. G. Burgwitz, A. T. Palecki, I. Turner, M. E. Podolsky. In the monograph of V. I. Surkin [1] it was shown that at the present time in the development of bearing designs connecting rod head - finger there is a tendency to reduce the amount of oil supplied to them. Most challenging in this way is the preservation of the limit temperature of the bearing below the critical.

\section{Equations, mathematics and algorithm output}

In the book of V. I. Surkin [1] an approximate mathematical model is constructed, which describes the relationship of output parameters of piston pin bearings with operational and structural factors. The model is based on the method of M. V. Korovchinsky for hydrodynamic calculation of statically loaded plain bearings [2].

This paper presents an algorithm, a program, and the results of calculations made on the basis of an approximate mathematical model of V. I. Surkin.

The searched parameters are: $l$ - iston head length; $\Delta$ - diametrical bearing clearance; $\mu$ - dynamic viscosity of the oil.

Specified (non-changing parameters):

$P z=119424 \mathrm{H} ; P=10470 \mathrm{H} ; \omega=30,1 \mathrm{~s}^{-1} ; a=0,039 \mathrm{~m} ; b=0,002 \mathrm{~m}$;

$p_{M}=400000$ PA-grease supply pressure;

$\mathrm{c}=2094 \mathrm{~J} /\left(\mathrm{kg}^{*} \mathrm{C}\right)$ - specific heat capacity of the oil;

$\gamma=883 \mathrm{gk} / \mathrm{m}^{3}$ - specific gravity of oil; $d=0,06 \mathrm{~m}$ is the diameter of the piston.

The required parameters:

$l$ - is the length of the piston head; $\Delta$ - diametrical bearing clearance; $\mu$-dynamic viscosity of the oil.

Initial value:

$l=0,049 \mathrm{~m} ; \Delta=0,023 \mathrm{~m} ; \mu=0,005 \mathrm{~m}$. 


\section{Restrictions:}

$$
\begin{aligned}
& 0,049 \leq l \leq 0,067 ; \quad 0,045 \leq d \leq 0,06 ; \quad 0,023 \leq \Delta \leq 0,056 \text {; } \\
& 0,005 \leq \mu \leq 0,01 ; \quad 2 \leq h \text {; }
\end{aligned}
$$

$P \max <250 \mathrm{MPa}$ - maximum hydrodynamic pressure;

$P z<50 \mathrm{MPa}-\mathrm{MPa}$-criterion for evaluation of dynamic load bearing in conditions of semi-liquid and boundary friction;

$\Delta T<40{ }^{\circ} \mathrm{C} \quad$ - with the increment of temperature of the lubricating layer;

$0,04 \leq \chi \leq 0,99$ - eccentricity;

$0,4 \leq l / d \leq 1,5$ - he ratio of the length of the piston head to the piston diameter.

Mathematical model of the bearing is a system of equations for the calculation of its main hydrodynamic parameters:

$$
\left\{\begin{array}{l}
h_{\min }=0,5 \Delta(1-\chi) \\
p_{\max }=k \frac{P}{l d} \\
N=0,5 f P \omega d \\
Q=0,5 \Delta \omega l d\left(q_{1}+q_{2}+q_{3}\right) \\
\Delta T=\frac{P f}{l c \gamma \Delta\left(q_{1}+q_{2}+q_{3}\right)} .
\end{array}\right.
$$

Calculation of dimensionless parameters included in the mathematical model.

The relative eccentricity $\chi$ :

$$
\chi=\frac{\ln \frac{P \Delta^{2}}{\left[-A_{1}(l / d)^{2}+A_{2}(l / d)-A_{3}\right] \mu \omega l d^{3}}}{A_{4}(l / d)^{2}-A_{5}(l / d)+A_{6}}
$$

where $A_{1}=0,0066 ; A_{2}=0,0524 ; A_{3}=0,0152 ; A_{4}=1,085 ; A_{5}=3,3011 ; A_{6}=8,1291-$ approximation coefficients;

$l / d$ - is the ratio of the length of the piston head to the diameter of the piston.

The minimum thickness of the lubricant layer is determined by the formula:

$$
h_{\min }=0,5 \Delta(1-\chi) \text {, (micrometer). }
$$

$k-$ is the coefficient calculated by the formula:

$$
k=1,7151(l / d)^{-0,479}\left(\frac{P \Delta^{2}}{\mu \omega l d^{3}}\right)^{0,341(l / d)^{0,216}}
$$

The maximum hydrodynamic pressure in the lubricant layer is determined by the expression:

$$
p_{\text {max }}=k p=k \frac{P}{l d} \quad, \quad(\mathrm{~Pa})
$$

The approximation formula for $f / \psi$ has the form: 


$$
\frac{f}{\psi}=\left[A_{1}(l / d)^{-A_{2}}\right] \chi^{2}-\left[A_{3}\left(l / d^{-A_{4}}\right)\right] \chi+A_{5}(l / d)^{-A_{6}}
$$

$f$ - friction coefficient of sliding:

$$
f=\frac{f}{\psi} \psi=\frac{f}{\psi} \frac{\Delta}{d}
$$

where $A_{1}=14,851 ; A_{2}=1,511 ; A_{3}=33,858 ; A_{4}=1,38 ; A_{5}=19,46 ; A_{6}=1,256$.

The power loss due to friction (the amount of heat released in the bearing per unit time):

$$
N=W=0,5 f P \omega d_{(\mathrm{BT}),}
$$

Coefficient of lubrication flow through the ends of the loaded zone:

$$
\begin{aligned}
& q_{1}=-\left[A_{1}(l / d)^{2}-A_{2}(l / d)+A_{3}\right] \chi^{2}+\left[A_{4}(l / d)^{2}-A_{5}(l / d)+A_{6}\right] \chi- \\
& -\left[A_{7}(l / d)^{2}-A_{8}(l / d)+A_{9}\right],
\end{aligned}
$$

where $A_{1}=0,193 ; A_{2}=0,7179 ; A_{3}=0,8627 ; A_{4}=0,3379 ; A_{5}=1,1429 ; A_{6}=1,236$; $A_{7}=0,0887 ; A_{8}=0,2714 ; A_{9}=0,2481$.

Coefficient of lubricant flow through the ends of the unloaded zone:

$$
q_{2}=\frac{\left(A_{1} \chi^{2}+A_{2} \chi+A_{3}\right) \Delta^{2} p_{M}}{\mu \omega l^{2}},
$$

where $A_{1}=0,3558 ; A_{2}=0,1131 ; A_{3}=0,1833 ; \quad p M$ - pressure lubrication.

Coefficient taking into account the increase in the lubricant flow through the ends in the presence of two side pockets on the bearing surface:

$$
q_{3}=\frac{\left(-A_{1} \chi^{2}+A_{2} \chi-A_{3}\right) \Delta^{2} a b p_{M}}{\mu \omega l^{2} d 0,5(l-a)} .
$$

where $A_{1}=0,3848 ; A_{2}=0,5276 ; A_{3}=0,0479 ; a, b-$ the width and height of the oil pocket.

Dimensionless coefficient of the expiration of lubricant calculated according to the formula:

$$
q=q_{1}+q_{2}+q_{3}
$$

Amount of lubricant flowing through the bearing ends per unit time:

$$
Q=0,5 \Delta \omega l d q,(\mathrm{~L})
$$

The magnitude of the increment of the temperature of the lubricating layer:

$$
\Delta T=\frac{P f}{l c \gamma \Delta q},
$$


where $c$-specific heat of oil, $\gamma$ - the specific gravity of the oil.

The solution of the optimization problem depends on the main requirements for the optimization object. For sliding bearings, such requirements may be: work with a minimum lubrication flow and simultaneously with a minimum temperature increment of the lubricant layer; work with a minimum lubrication flow and a minimum coefficient of friction; work with a minimum relative eccentricity and a minimum coefficient of friction, etc.

The most difficult is to keep the limit temperature in the lubrication layer of the bearing below the critical level. With this in mind, the optimization process searches for such control parameters $l, \Delta, \mu$, that would provide the maximum reduction of lubricant consumption $Q$ with a minimum increment of the lubricant layer temperature $\Delta T$.

$$
V=10^{8} \mathrm{Q}+\Delta T-\min
$$

Optimization of bearing parameters is carried out by the method of gradient descent [3]. The problem was solved with the help of the program developed by the author in the MATLAB environment.

The values determined depend on three parameters: the angular extent of the lubricant layer or coverage angle $\left(120^{\circ}, 180^{\circ}\right)$, he relative eccentricity $\chi(0,4 \div 0,99)$ and the ratio $l / d(0,4 \div 1,5)$. The bearings under consideration operate under conditions of low angular velocities of the thorn and low viscosity of the oil.

The optimization algorithm the method of steepest descent:

1. Data entry.

2. Selected initial parameters $l, \delta, \mu$. Refer to the procedure for computing the target function $V$.

3. The calculation of the approximate values of the components of the objective function

$$
\operatorname{grad} V \approx \sum_{i=1}^{n} \frac{\Delta V_{i}}{\Delta X_{i}} \vec{j}_{i}
$$

4. Calculation and evaluation of the conditions of completion of the search

$$
\sum_{i=1}^{n}|\operatorname{grad} V| \leq E
$$

where $E$ - characterizes the accuracy of the search.

5. Moving along the anti-gradient vector and calculating new parameters

$$
\frac{L}{D_{i+1}}=\frac{L}{D_{i}}-a_{1} \operatorname{grad} V\left(\frac{L}{D}\right) ; \delta_{i+1}=\delta_{i}-a_{1} \operatorname{grad} V(\delta) ; \mu_{i+1}=\mu_{i}-a_{1} \operatorname{grad} V(\mu) .
$$

When the boundary parameter is reached, the movement on it stops and the value is taken equal to the boundary.

6. Check at each new constraint execution point. If the restrictions are met, the transition to 10 is made.

7. The construction of the constraint functions..

8. The calculation of the gradient of the function $q(j ; \delta ; \mu)$.

9. The movement vector antigradient function $q(j ; \delta ; \mu)$ until then, until all constraints are met. 
10. The calculation of the increment function

$$
\Delta V=V i-V i_{-1} .
$$

Under the conditions of the $\Delta V \geq 0$ the movement vector $V$ gradient stops.

11. If the restrictions are violated 13 .

12. The transition to 3 .

13. The output of the results.

Optimization of medium-cycle hydrodynamic parameters of the piston pin bearing of the engine is carried out according to the scheme shown in figure 1. The main structural elements of the scheme are: a mathematical model of the bearing, the input and output parameters, the system constraints, objective function, the search procedure of optimal parameters.

For convenient work with the program, the author has developed an interface. The program interface is shown in the figure 1.

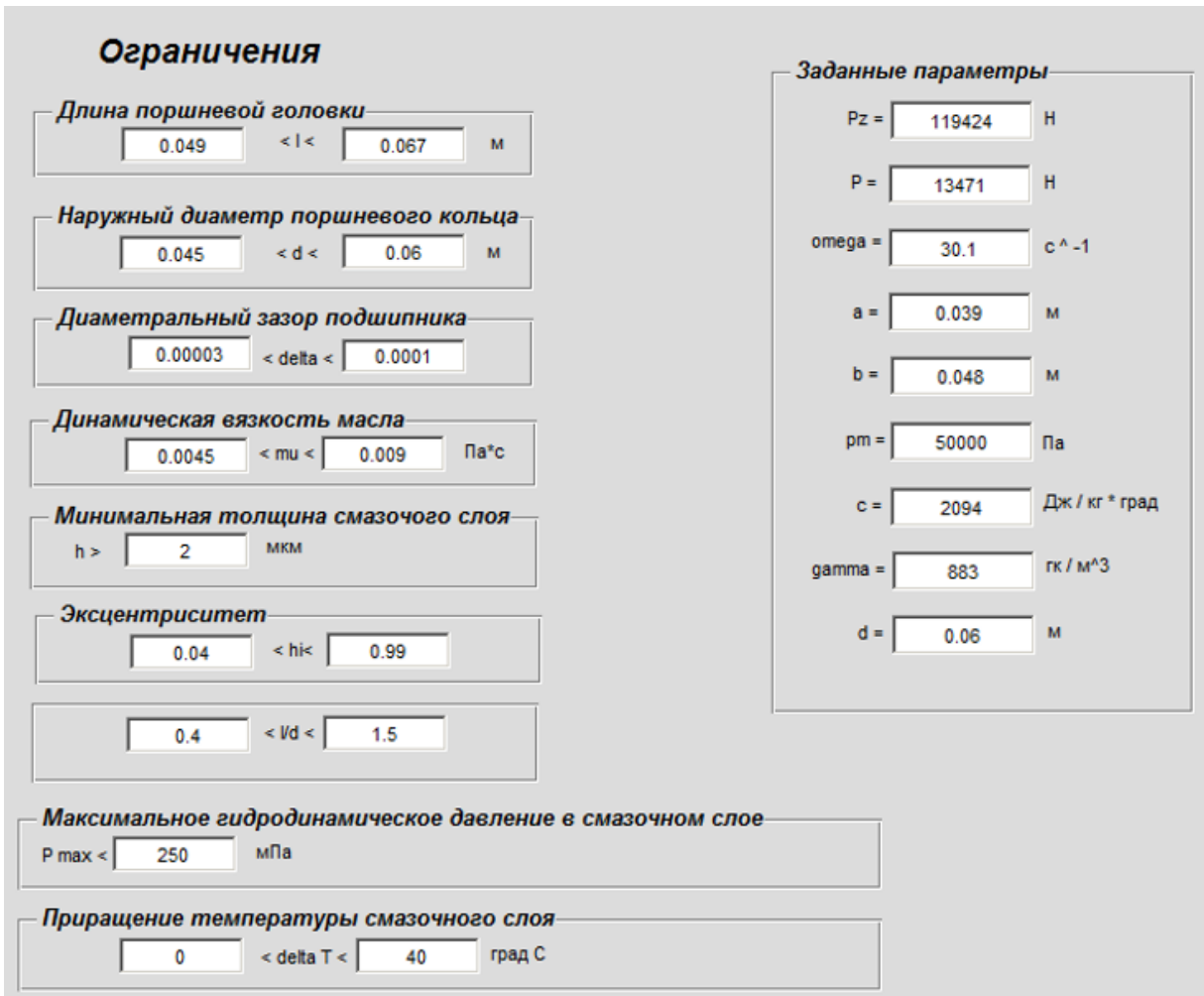



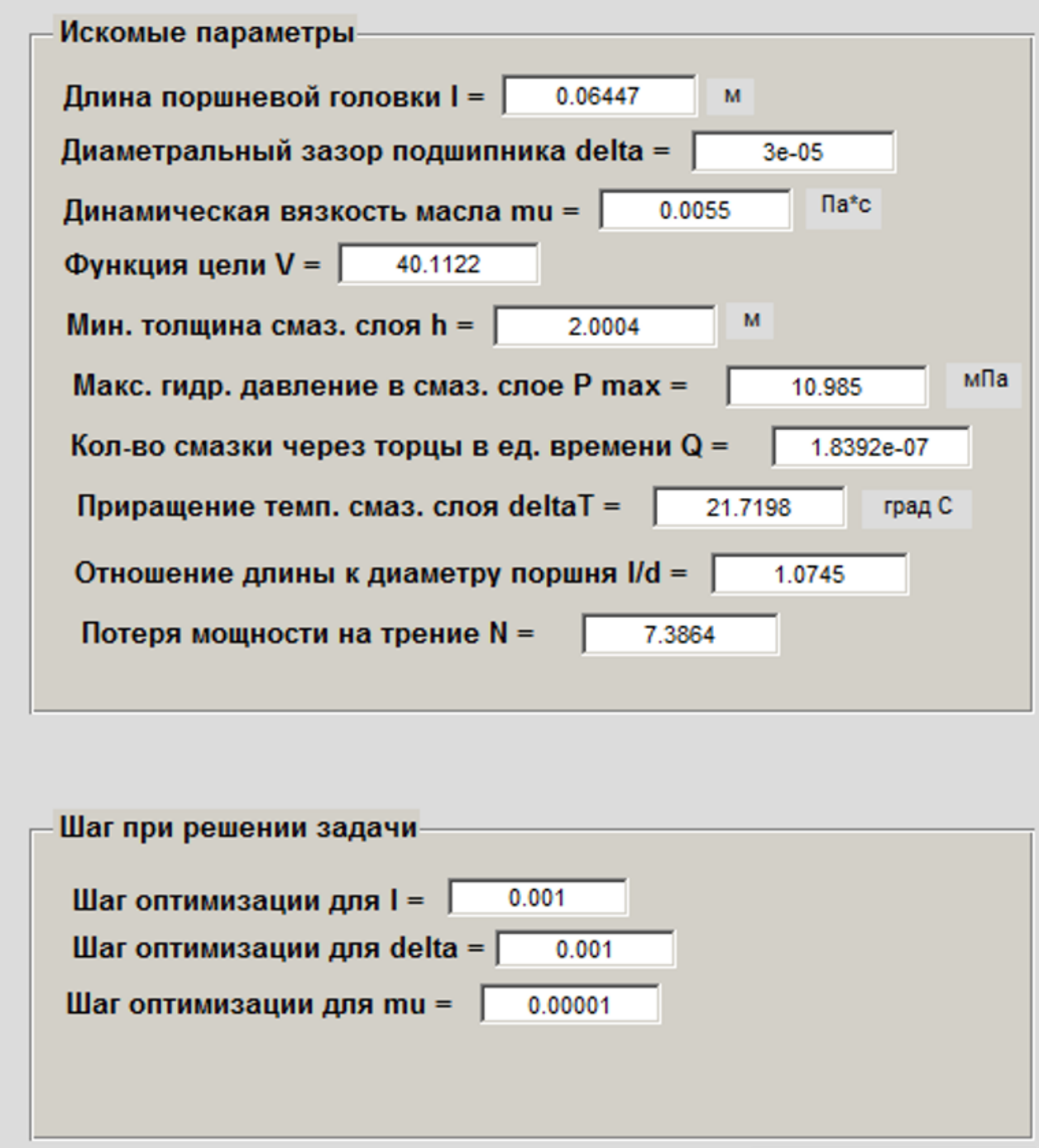

\section{Решить задачу}

Fig. 1. Interface of the optimization program developed by the author.

\section{Output}

A mathematical model of a piston finger bearing of an internal combustion engine suitable for optimization of its hydrodynamic parameters is developed. The technique of optimization of hydrodynamic parameters of a bearing is created. The algorithm and program of optimization of the piston pin bearing of the engine are developed. With specified constraints and input parameters, the program allows you to calculate the optimal dimensions of the bearing. Results of calculations allow to receive practical recommendations on improvement of designs of bearings. 


\section{References}

1. V.I Surkin., B.V. Kurchatov Smazka traktornykh dvigateley (monografiya). Chelyabinsk: izd-vo CHGAA, (2009)

2. M.V. Korovchinskiy Teoreticheskiye osnovy raboty podshipnikov skol'zheniya. M .: Mashgiz, (1959)

3. I.A. Solov'yov Vychislitel'naya matematika na smartfonakh, kommunikatorakh i noutbukakh s ispol'zovaniyem programmnykh sred Python: uchebnoye posobiye / I. A. Solov'yov, A. V. Chervyakov, A. YU. Repin. SPb .: Lan' (2011)

4. O.G. Zavyalov Directions and problems of development at the hydrodynamical theory of lubricant, sliding support with gas lubricant, Scientific review, M.: Nauka, branch of ZAO ALKOR, № 5, pp. 2 - 4 (2005) 